4th Int. Conf. on Ion Sources. Bensieim, Germany, 9/30-10/4/91.

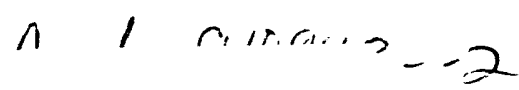

BNL --45962

DE92 000134

\title{
THE NEW BNL POLARIZED NEGATIVE ION SOURCE*
}

\begin{abstract}
A.I. Hershcovitch, J.G. Alessi, B. DeVito, and A.E. Kponou Brookhaven National Laboratory, Upton, NY 11973 USA
\end{abstract}

\section{Recrived by OSTI}

\section{Abstract}

OCT 031991

A new ground state source of negative hydrogen ions with polarized nuclei $\left(\overrightarrow{\mathrm{H}}^{-}\right)$is being developed at BNL. Extensive developmental research has been aimed at improving each element of $\left(\overrightarrow{\mathrm{H}}^{-}\right)$production: cold $\mathrm{H}^{\cdot}$ beam, spin selection and focusing magnets, and ionizer. These elements have recently been integrated into a source. A first test with the accomodator nozzle cooled only to liquid nitrogen temperatures resulted in $5 \mu \mathrm{A}$ of $\mathrm{H}^{-}$. Tests at liquid helium temperatures are now beginning.

\section{DISCLAIMER}

This report was prepared as an account of work sponsored by an agency of the United States Government. Neither the United States Government nor any agency thereof, nor any of their employees, makes any warranty, express or implied, or assumes any legal liability or responsibility for the accuracy, completeness, or usefulness of any information, apparatus, product, or process disclosed, or represents that its use would not infringe privately owned rights. Reference herein to any specific commercial product, process, or service by trade name, trademark, mar:ufacturer, or otherwise dues not necessarily constitute or imply its endorsement, recommendation, or favoring by the United States Government or any agency thereof. The views and opinions of authors expressed herein do not necessarily state or reflect those of the United States Government or any agency thereof.

*Work performed under the auspices of the U.S. Department of Energy . 


\section{Introduction}

Since 1984, the Brookhaven Alternating Gradient Synchrotron (AGS) has had the ability to accelerate polarized protons. The polarized $\mathrm{H}^{-}$ion source used (PONI-1), has a ground state atomic beam source and $\mathrm{Cs}^{\circ}$ beam ionizer. since this source produces only $-40 \mu \mathrm{A}$ (three orders of magnitude less beam than normal $\mathrm{H}^{-}$operation for the AGS), higher polarized intensities were desirable. A program was begun to work on developments which could lead to a new source producing higher intensities. We settled on three areas of research; one being the development of a $6 \mathrm{~K}$ atomic beam state, the second involved experimenting with various magnets for spin selection and focusing, and the third being the use of a $D^{-}$charge exchange ionization scheme. Research was concluded on all individual elements and a few months ago a combined source made up of a cold atomic beam stage, a two-magnet system, and a ring magnetron ionizer was assembled.

Figure 1 shows the combined system. From left to right, shown are a cold atomic beam stage for generation of high flux, low vslocity $H^{*}$ atoms. Next is a two-magnet spin selection "and focusing system, followed by a ring magnetron $D^{-}$ionizer. The quadrupole mass spectrometer on the far right-hand side is used for tuning up the atomic beam stage, while the dipole magnets is used to separate the extracted $\mathrm{H}^{-}$and $\mathrm{D}^{-}$beams. 
I. Cold Atomic Beam

In Ref. 1, the setup and results are described for our first attempt to produce a high flux, low velocity $H^{\cdot}$ beam by passage of the atoms through a $6 \mathrm{~K}$ copper accommodator section at the exit of an $\mathrm{rf}$ dissociator. At $6 \mathrm{k}$, time-of-flight measurements of the velocity distribution showed that the beam had a most probable velocity of $680 \mathrm{~m} / \mathrm{s}$, a FWHM of approximately $200 \mathrm{~m} / \mathrm{s}$, and a forward flux of $9.4 \times 10^{18} \mathrm{H} / \mathrm{sr} / \mathrm{s}$. However, after re-examining the old data and comparing it with magnetic focusing results, the most probable velocity now seems to have been about $500 \mathrm{~m} / \mathrm{s}$. The atomic beam stage has since been further improved to the configuration that is presently used. Shown in Figure 1 is a Pyrex rf dissociator tube whose exit is cooled by liquid nitrogen via a cooled copper clamp around the outside of the Pyrex. Following this, there is $a 0.3$ mm gap, and then the liquid helium cooled copper accommodator. The accommodator channel is $35 \mathrm{~mm}$ long, $70 \%$ of which has a $5 \mathrm{~mm}$ diameter. In the following $10 \mathrm{~mm}$ long section, which tapers out to a final diameter of $10 \mathrm{~mm}$, inserts have been used to reduce this diameter to 3 and $6 \mathrm{~mm}$ for parametric studies. Further details, including the reasons for these changes, can be foúnd in references 2 and 3 . Following the accommodator there is a skimmer and a stack of 5 charcoal coated cryopanels cooled to a temperature lower than that of liquid helium. 
with this new atomic beam stage and an accommodator temperature of $6 \mathrm{~K}$, a pulsed $\mathrm{H}^{*}$ density of $6 \times 10^{11} / \mathrm{cm}^{3}$ was measured $90.5 \mathrm{~cm}$ away (before adding the ring magnetron to the system). This density, measured via a quadrupole mass spectrometer and without any focusing of the atoms, was an improvement by a factor of 34 over the density measured with the atomic beam in Ref. 1. It should be noted that these results were obtained earlier 4 with one difference: the accommodator was followed by 10 cryopanels.

\section{Spin Selection and Focusing Magnets}

A number of spin selection and focusing schemes were tried.4,5 Focusing the neutral hydrogen beam with a superconducting solenoid was not successful at peak beam intensity due, we believe, to intrabeam scattering in the solenoid. This conclusicn is based on the observation that focusing decreased with increasing beam density. On the basis of this observation, the $\mathrm{H}^{*}-\mathrm{H}^{*}$ scattering cross section has been inferred ${ }^{6}$ to be $100 \AA^{2}$, somewhat higher than values previously reported in the literature.

Modifying the solenoid to give it a more open geometry for improved pumping was not practical, hence we decided to build a $20 \mathrm{~cm}$ long permanent magnet sextupole having a $4 \mathrm{~cm}$ bore diameter and a pole-tip field of $7 \mathrm{~kg} .5$ This individual magnet 
from which the poles were assembled was made from $\mathrm{Nd}-\mathrm{Fe}$ and specially coated to resist attack lyy atomic hydrogen. Azimuthally machined slots in the yoke allowed for additional (radial) pumping of the bore. No significant focusing was observed with this magnet, and our inability to vary the magnetic field was a serious drawback since subsequent simulations showed that the focusing was very sensitive to beam velocity. We have established that the strength of the magnet did not match the $680 \mathrm{~m} / \mathrm{s}$ velocity, based on which the magnet was designed. Furthermore, correlating simulations with experimental results indicated a beam velocity in the $500 \mathrm{~m} / \mathrm{s}$ range. 3

Finally, satisfactory (but non-optimized) performance has been obtained from our present two-magnet system. The permanent magnet was reduced to a length of $10 \mathrm{~cm}$ and a conventional electromagnet sextupole, which is also $10 \mathrm{~cm}$ long and has a 3.6 cm aperture, was added. A peak pole tip field of $8.5 \mathrm{~kg}$ was reached with this magnet. As shown in Figure 1, the permanent magnet is nearer to the nozzle because of its larger bore and pumping slots. The permanent magnet can be moved both vertically (in and out of the beam), and axially (up to $4 \mathrm{~cm}$ ).

Prior to adding the ionizer to the system, a number of experimental runs were performed. In these experiments, the quadrupole mass spectrometer was placed $70 \mathrm{~cm}$ from the accommodator exit (roughly at the ionizer location). Table I shows the 
focusing factor (FF), defined as the ratio of $H^{\cdot}$ densities with magnet on to magnet off, of the leading edge of the $H^{*}$ pulse, with the permanent magnet in line and the electromagnet at its maximum field, as a function of the unfocused leading edge density, $\mathrm{N}_{\mathrm{U}}$, and the range of the accommodator temperature, $\mathbf{T}_{\text {acc }}$

From Table I it i; obvious that the scattering problem still exists (although it is substantially reduced from that with the superconducting solenoid). The focusing factor decreases with an increase in density and it increases with the increase in accommodator temperature (forward beam velocity). Some additional characteristics of this focusing system are: (1) FF kept on increasing with increasing magnet field strength of the electromagnet sextupole; (2) FF changed very little with axial motion of the permanent magnet sextupole; (3) vertical position of the permanent magnet sextupole had a substantial effect on the focusing--FF reduced to $60 \%$ of its peak value when this sextupole was moved $3 \mathrm{~mm}$ off axis.

It should be noted that for the four lowest densities, the electromagnet was pulsed and the peak pole tip field of the electromagnet sextupole was $8.5 \mathrm{kG}$, while the magnet was operated dc and the field was limited to $6.3 \mathrm{kG}$ for the four higher densities. Although scattering still exists, this two-magnet 
system can deliver a $\overrightarrow{\mathrm{H}}^{\cdot}$ density in excess of $3 \times 10^{12} \mathrm{~cm}^{-3}$ into the ionizer.

Table I. Peak focusing factor versus unfocused density and accommodator temperature range.

$\begin{array}{lll}T_{\text {acc }} & 4-8 \mathrm{~K} & 25-30 \mathrm{~K} \\ \mathrm{~N}_{\mathrm{u}} & & 26 \\ 1 \times 10^{9} \mathrm{~cm}^{-3} & & \\ 2 \times 10^{9} \mathrm{~cm}^{-3} & 12.75 & 13.6 \\ 2.5 \times 10^{9} \mathrm{~cm}^{-3} & & \\ 5 \times 10^{9} \mathrm{~cm}^{-3} & 10.8 & 8.8 \\ 9.8 \times 10^{10 \mathrm{~cm}^{-3}} & & \\ 1.6 \times 10^{11} \mathrm{~cm}^{-3} & 5.75 & 8.29 \\ 3.5 \times 10^{11} \mathrm{~cm}^{-3} & 3.6 & 6.29 \\ 4 \times 10^{11} \mathrm{~cm}^{-3} & 2.3 & \end{array}$

III. Ring Magnetron Ionizer

Ionization in this source is done by $D^{-}-\vec{H}^{\cdot}$ charge exchange. A radial $D^{-}$beam is generated by a surface plasma ring magnetron. Initial experiments ${ }^{7}$ with an unpolarized $\mathrm{H}^{\bullet}$ beam were very encouraging in producing $500 \mu \mathrm{A}$ of $\mathrm{H}^{-}$for an $\mathrm{H}^{\cdot}$ 
density of $10^{12} / \mathrm{cm}^{3}$. However, subsequent experiments ${ }^{2}, 3$ with a polarized room temperature beam revealed a large loss in ionization efficiency which seems to be primarily due to poorer pumping of $D_{2}$ away from the ionizer region, which causes attenuation of the incoming $\overrightarrow{\mathrm{H}}^{\cdot}$ beam. Therefore, only $15 \mu \mathrm{A}$ of $\mathrm{H}^{-}$has been measured for an $\mathrm{H}^{\cdot}$ density of $\sim 1 \times 10^{11} / \mathrm{cm}^{3}$ at the ionizer. The cold atomic beam and ring magnetron ionizer have now been combined on a test stand.

IV. Preliminary Experimental Results

Although the atomic beam stage and focusing magnets were designed for operation at 4-25 $\mathrm{K}$, the source was run with the accommodator cooled to liquid nitrogen temperature. $5 \mu \mathrm{A}$ of $\mathrm{H}^{-}$were extracted for an estimated $\overrightarrow{\mathrm{H}}^{\cdot}$ density of about $7 \mathrm{x}$ $10^{10} \mathrm{~cm}^{-3}$ in the ionizer region. Experiments with the atomic beam cooled to liquid helium temperature are now beginning. 


\section{References}

1. A. Hershcovitch, A. Kponou, and T.O. Niinikoski, Rev. sci. Instrum. 58,547 (1987).

2. A. Hershcovitch, A. Kponou, and B. Devito, Proceedings of the International Workshop on Polarized Ion Sources and Polarized Gas Jets, February, 1990, KEK Report \#90-15 Y. Mori, Ed., p. 109 .

3. A. Kponou, A. Hershcovitch, J.G. Alessi, B. DeVito, and C.R. Meitzler, AIP Conf. Proceedings \#210, A. Hershcovitch, Ed., Particle and Fields Series \#40, 1990, p. 385.

4. A.I. Hershcovitch, A.E. Kponou, C.R. Meitzler, and T.O. Niinikoski, Rev. Sci. Instrum. 61, 2368 (1990): RSI 61, 3927 (1990).

5. J.G. Alessi, B. DeVito, A. Hershcovitch, and C.R. Meitzler, LBL, 1989, Rev. Sci. Instrum. 61, 403 (1990).

6. A. Hershcovitch, Phys. Rev. Lett. 63,750 (1989).

7. J.G. Alessi, Helvetica Physica Acta 59, 547 (1986).

Figure Caption

Figure 1 - Diagram of the Experimental Arrangement. 


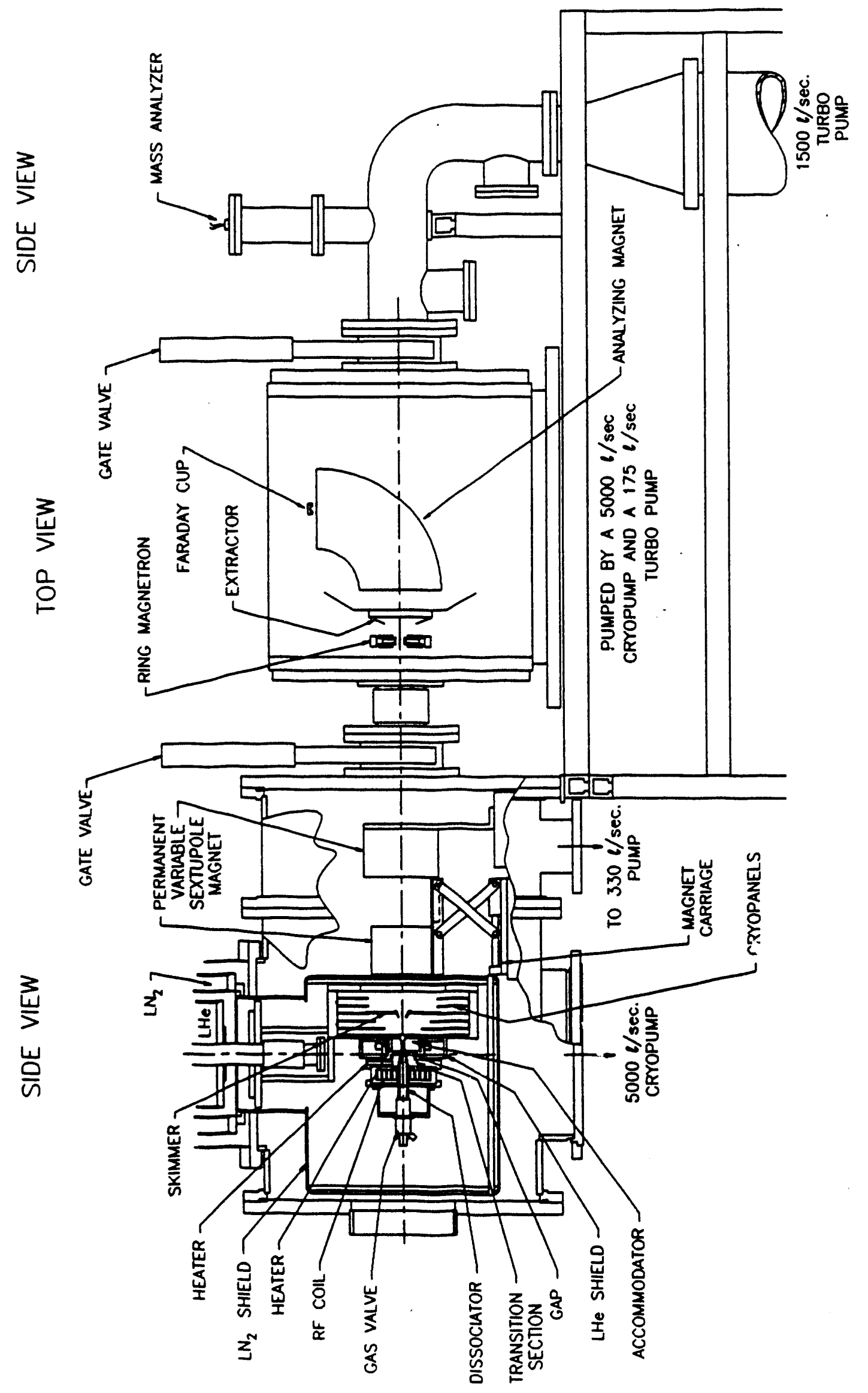



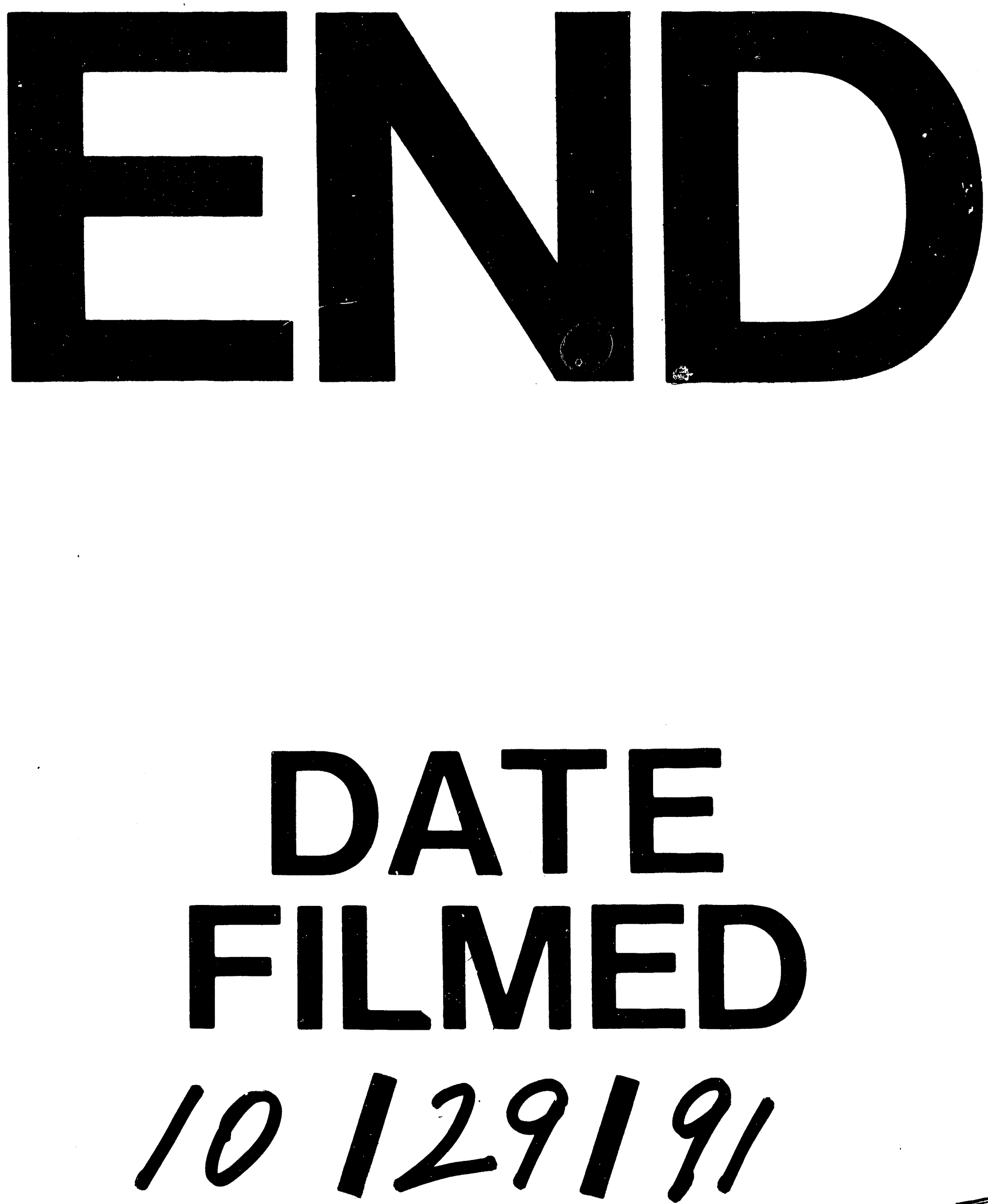
